\title{
Gastric heterotopic pancreas masquerading as a stromal tumor: A case report
}

\author{
MAOSONG LIN ${ }^{1}$, YIWEI FU ${ }^{1}$, HONG YU ${ }^{2}$ and JUNXING HUANG ${ }^{3}$ \\ Departments of ${ }^{1}$ Gastroenterology, ${ }^{2}$ Pathology and ${ }^{3}$ Oncology, Taizhou People's Hospital, \\ Taizhou, Jiangsu 225300, P.R. China
}

Received October 12, 2014; Accepted July 28, 2015

DOI: 10.3892/ol.2015.3593

\begin{abstract}
Heterotopic pancreas (HP), a rare condition that is generally asymptomatic, is an aberration in the developmental profile of the pancreas. While it can occur in any location in the gastrointestinal tract, it is most typically found in the antrum of the stomach and is usually wrongly considered to be a submucosal tumor (SMT). Despite advances in diagnostic modalities, a HP still poses a diagnostic dilemma to clinicians. Invasive surgery or endoscopic resection have often been inappropriately applied in cases of an ectopic pancreas due to the difficulty in distinguishing it from neoplastic SMTs, such as gastrointestinal stromal tumors (GISTs). The present study reports the unusual case of a middle-aged female with an SMT at the lesser curve of the mid-body of the stomach, which was initially diagnosed as a GIST through endoscopic ultrasonography and computed tomography. However, following removal by endoscopic submucosal dissection, this lesion was finally histopathologically confirmed as an HP. Therefore, although it is rare, the possibility of an HP should always be considered when diagnosing an extramucosal gastric mass. The precise pre-operative diagnosis of this entity may avoid unnecessary extensive treatment intervention.
\end{abstract}

\section{Introduction}

Heterotopic pancreas (HP), also known as ectopic or aberrant pancreas, is a congenital disorder with an occurrence rate of $0.5-13 \%$ in the general population (1). HP has no any vascular or anatomical communication with the normal pancreas, yet

Correspondence to: Dr Maosong Lin, Department of Gastroenterology, Taizhou People's Hospital, 210 Yingchun Road, Taizhou, Jiangsu 225300, P.R. China

E-mail:1ms0605@163.com

Professor Junxing Huang, Department of Oncology, Taizhou People's Hospital, 210 Yingchun Road, Taizhou, Jiangsu 225300, P.R. China

E-mail: hjxtz@sina.cn

Key words: heterotopic pancreas, gastrointestinal stromal tumor, submucosal tumor exhibiting the histological features of pancreatic acinar formation, the development of ducts and the presence of islets of Langerhans, with an independent blood supply (2-4). The heterotopic organ often remains silent, but may occasionally be symptomatic, including gastrointestinal bleeding, gastric outlet obstruction, gastric ulceration, pancreatitis and even malignant degeneration (5-7).

Appearing as intraluminal protrusions with normal overlying mucosa, HPs are usually diagnosed as submucosal tumors (SMTs) at first during routine endoscopy. Despite the advent of novel diagnostic modalities, including endoscopic ultrasonography (EUS), computer tomography (CT) and even EUS-guided fine-needle aspiration (EUS-FNA), the differentiation from a neoplasm remains a clinical challenge (8-10). Invasive surgery or endoscopic resection are often inappropriately performed in HP cases due to tissue sampling errors and the difficulty in forming a pre-operative diagnosis on imaging $(11,12)$. However, asymptomatic HP is benign and can be monitored long-term without further intervention. Therefore, the ability to pre-operatively distinguish HPs from neoplastic SMTs, such as gastrointestinal stromal tumors (GISTs), is extremely important.

The present study describes a case with a lesion located on the lesser curvature of the gastric body, which was initially diagnosed as GIST through EUS and CT, until finally being confirmed as an HP. The study also presents a brief literature review concerning this relatively rare disorder. Written informed consent was obtained from the patient for the publication of this study.

\section{Case report}

A 48-year-old female with no past medical history was referred to Taizhou People's Hospital (Taizhou, Jiangsu, China) on September 9, 2009, due to recurrent epigastric pain that had persisted for more than one month. A physical examination revealed that the patient was in good health without weight loss. The abdomen was soft and non-tender, with no palpable mass. Moreover, the patient's vital signs, and respiratory and vascular systems were normal. Routine blood tests, including amylase levels, biochemistry, and plain chest and abdominal ultrasonography, were unremarkable. Tumor marker levels were also normal. Upper gastrointestinal endoscopy revealed a submucosal tumor-like lesion $\sim 20 \mathrm{~mm}$ in diameter located on 

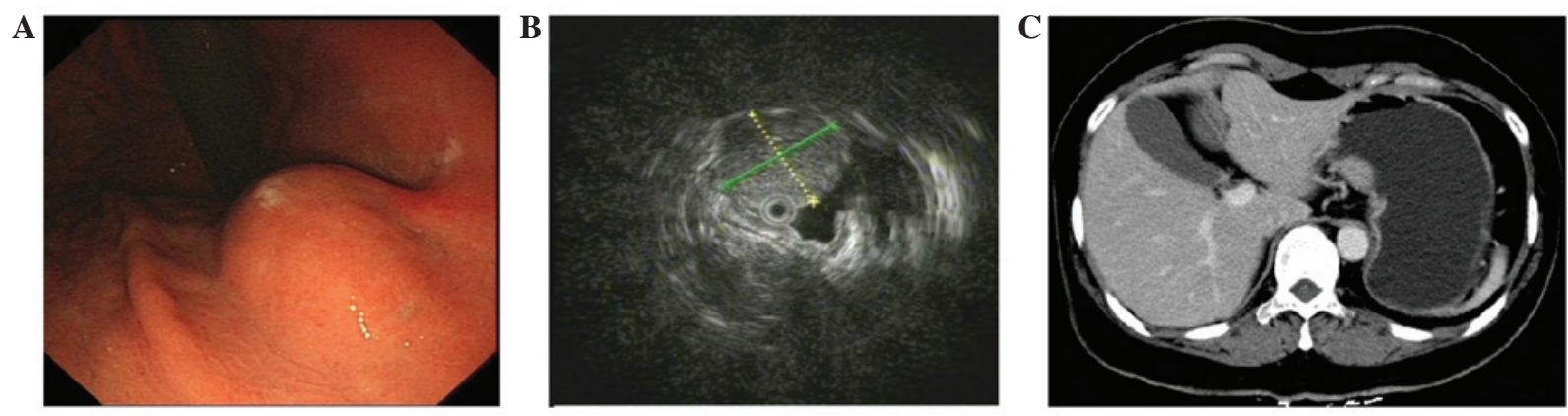

Figure 1. Imaging showing a solid tumor mass under the mucosal membrane located on the lesser curvature of the middle gastric body. (A) Endoscopic image ra evealing a 15-mm gastric submucosal tumor located in the body. (B) Endoscopic ultrasonography image obtained with a 20-MHz catheter probe revealing low-echogenicity mass under the gastric wall submucosal muscularis propria, with a clear boundary and uneven internal echogenicity. (C) Contrast-enhanced abdominal computed tomography image demonstrating a mass, $23 x 11 \mathrm{~mm}$ in size, in the gastric body.
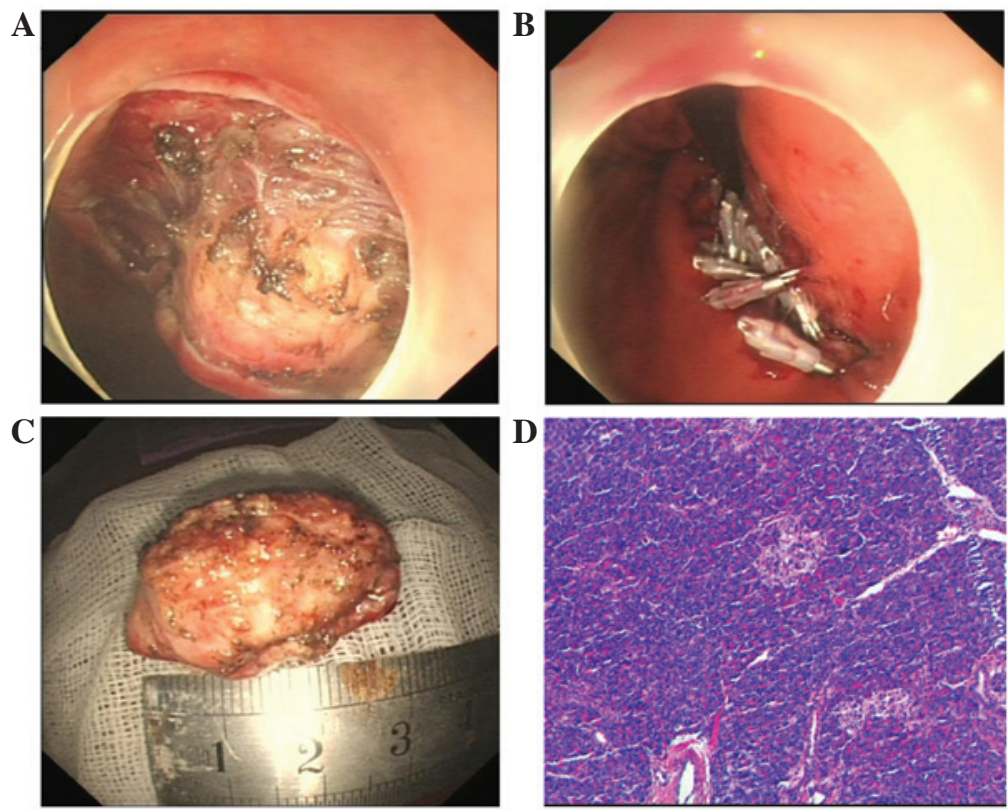

Figure 2. Endoscopic submucosal dissection (ESD) of the ectopic pancreas. (A) Endoscopic direct image showing a soft, yellow tumor. (B) Nylon loop with clips used to suture the mucosal defects and perforation of the stomach on endoscopy. (C) The inner surface of the resected specimen. (D) Histopathological findings revealing only acinar cells in the tissue sample obtained by the bloc biopsy (hematoxylin and esoin staining; magnification, x100).

the lesser curvature of the middle gastric body, but the mucosa itself was normal (Fig. 1A). EUS was further performed with a radial scanning $20-\mathrm{MHz}$ catheter probe being passed through the instrument channel of a one-channel endoscope. EUS examination demonstrated a hypoechoic lesion, 16x17 mm in size, mostly originating from the muscularis propria (Fig. 1B). In addition, contrast-enhanced CT revealed a mild homogeneously-enhanced mass measuring 20x15 mm in the mid-body of the stomach (Fig. 1C). Based on these findings, the lesion was initially suspected to be a GIST. Considering that this lesion would subsequently be removed, either through exploratory laparoscopy or endoscopic dissection, EUS-FNA was not performed to acquire biopsy specimens.

The patient opted for endoscopic intervention. Therefore, after obtaining informed consent, an endoscopic resection was performed. Firstly, the margins of the lesion were marked by a needle knife, and a submucosal saline injection with a small amount of epinephrine $(0.025 \mathrm{mg} / \mathrm{ml})$ and indigo carmine was used to lift the lesion. Next, a circumferential incision in the submucosa and a submucosal dissection around the lesion was performed with a hook knife (Fig. 2A). Subsequent to removal, the en bloc pathological specimen was mounted and oriented to facilitate histological examination (Fig. 2B), and the mucosal defects and a small perforation was sutured by combining a nylon loop with the clips (Fig. 2C). The patient experienced no post-operative complications and was discharged 7 days later. Unexpectedly, the histopathological examination of the lesion revealed a final diagnosis of a gastric HP, with acinar tissue architecture characteristic of an ectopic pancreas. The pancreatic acinar cells were located mainly in the gastric submucosa and partially in the muscularis propia (Fig. 2D). The overlying gastric mucosa was normal.

\section{Discussion}

First reported by Schultz in 1729 (13), with further histological confirmation provided by Klob in 1859 (14), HP is defined as pancreatic tissue without any anatomical or vascular continuity 
with the normal pancreas. Although its cause is unclear, several theories, including the 'theory of metaplasia', the 'theory of misplacement' and the latest addition, the 'theory of abnormalities of notch signaling', have been proposed to explain the pathogenesis and occurrence of pancreatic heterotopia (15-18). The most common site of this entity is the stomach, accounting for $25-38 \%$ of cases, followed by the duodenum (17-36\%) and jejunum (15-22\%). By contrast, an HP is rarely found in the esophagus, common bile duct, gallbladder, mesentery, spleen, mediastinum or fallopian tubes (19). In the stomach, $>95 \%$ of lesions are found in the antrum, mainly situated close to the greater curvature (20). However, in the present case, the ectopic pancreas was located on the lesser curvature of the middle gastric body, a relatively uncommon location for this rare disorder in the stomach.

To the best of our knowledge, the pre-operative diagnosis of an ectopic pancreas remains quite challenging despite the advancement in diagnostic tools; this has been demonstrated by the frequent inability to differentiate HP from neoplastic lesions warranting surgical excision. Imaging techniques such as EUS and CT are frequently used for gastrointestinal submucosal tumor diagnosis and may be of use in the diagnosis of gastric HP, but are not sufficiently specific for differential diagnosis. Endoscopically, HP in the stomach wall has been described as an elevated delomorphic submucosal tumor that presents with a normal overlying mucosa, with characteristic central umbilication (3), which was not featured in the present case. However, in more than half of recorded cases, the endoscopic view is not that specific, for example, the central dimpling is missing, as in the present case, and the tumor may therefore easily be misinterpreted as another submucosal tumor, such as a GIST, as occurred in the present case, or as another malignancy on endoscopic examination $(9,10)$. On EUS, HP is typically hypoechoic and heterogeneous, with indistinct margins. HP usually arises from the second, third and/or fourth layers of the gastrointestinal tract, or from a combination of the three (21). Meanwhile, GISTs are typically hypoechoic, homogeneous lesions with well-defined margins. However, these tumors can also occasionally present with ulcerations and irregular margins. The majority of GISTs originate from within the muscularis propria. Small lesions may originate from the muscularis mucosa (22). Although the imaging features of an ectopic pancreas, including a larger longest:shortest diameter ratio, a mural growth pattern, an antral location, third (submucosal) layer disruption, intermediate echogenicity and irregular margins, can occasionally aid in distinguishing HP from other submucosal gastrointestinal tumors, none of these findings, either individually or collectively, are characteristic of this entity, and no long-term studies have supported this description. Therefore, a surgical resection is required to confirm the diagnosis in the majority of circumstances $(8,9)$.

The definitive diagnosis of HP can be reached by the histopathological examination of the tissue. However, endoscopic biopsy performed using standard biopsy forceps most often leads to unremarkable results. Recently, the use of EUS-FNA has emerged as an important diagnostic technique for SMT (23). However, as this method exhibits limited diagnostic accuracy due to the small amount of tissue that can be collected, an improved method, such as ESD-based intervention or surgery, is required for tissue sampling (24). Histologically, based on the classification devised by Von Heinrich et al in 1909 and the subsequent modification by Gaspar Fuentes et al in 1973 , pancreatic heterotopia is divided into four types $(25,26)$. Type I shows typical pancreatic tissue with acini, ducts and islet cells, similar to the normal pancreas. Type II shows only pancreatic ducts, while type III has only acinar tissue and type IV (endocrine pancreas) has only islet cells. In the present study, the lesion was of type III, with acinar cells but no ducts or islet cells found in the specimen.

The majority of cases of ectopic pancreases, particularly those that are small, remain asymptomatic during the human lifespan. However, certain lesions, particularly those $>1.5 \mathrm{~cm}$, can exhibit non-specific symptoms, including abdominal pain and fullness, nausea and vomiting, weight loss, anorexia, anemia and melena. In certain cases, ectopic pancreases manifest as conditions that require emergency treatment, such as gastrointestinal bleeding, gastric outlet obstruction or perforation (27-30). These cases require further management involving surgery or endoscopical intervention.

There is currently an ongoing academic debate as to whether an ectopic pancreas should be excised. Supporters advocate the removal of this lesion as early as possible as a means of prophylaxis due to the fact that it can be a predisposing factor for all typical pancreatic disorders, from acute and chronic pancreatitis to neoplastic transformation $(2,3)$. by contrast, antagonists prefer conservative management, with only those patients with severe pain, actual disordered function or emergency presentations treated by surgical intervention (31). At present, selecting the optimal treatment is a challenge even for experienced clinicians. In our opinion, a precise pre-operative diagnosis through imaging and pathology, which may provide useful information, should be performed prior to deciding on the therapeutic strategy. EUS-FNA is useful for making an accurate histological diagnosis of the lesion, although its value requires further assessment and future improvements. In addition, an ESD-based method, such as that mentioned in the study by Kobara et al (24), can overcome the flaw of no adequate tissue samples being obtained from conventional biopsy and EUS-FNA (32), and can deeply improve the accuracy of diagnosing this disorder prior to management. As a result, when diagnosed with benign lesion characteristics through EUS and pathology, HPs, particularly the relatively small lesions and those in asymptomatic patients, do not require treatment. However, patients with symptoms do require further therapy. Three methods of treatment intervention currently exist: Classic laparotomy with wedge resection, laparoscopic sleeve resection and endoscopic submucosal dissection (33-35), the latter of which has been gaining in popularity over the last decade. Traditional surgical interventions may be preferred in less experienced centers due to the incorrect identification of ectopic pancreases, leading to unnecessary partial or total gastrectomies in certain patients. In the present case, an laparoscopic wedge resection was initially planned when considering the GIST features and relatively rare location. However, after successfully performing a technique that combined a nylon loop with clips to suture the mucosal defects and perforation of the stomach on endoscopy, the experienced endoscopist successfully removed the lesion. After seven days of follow-up, the patient did not demonstrate any complications, including abdominal pain or a fever. 
In conclusion, HP should always be considered when diagnosing extramucosal gastric masses. Precise pre-operative diagnostics may avoid misleading and unnecessarily excisions. ESD-based management in ectopic pancreases deserves further consideration and investigation in the future.

\section{References}

1. DeBord JR, Majarakis JD and Nyhus LM: An unusual case of heterotopic pancreas of the stomach. Am J Surg 141: 269-273, 1981.

2. Jiang LX, Xu J, Wang XW, Zhou FR, Gao W, Yu GH, Lv ZC and Zheng HT: Gastric outlet obstruction caused by heterotopic pancreas: A case report and a quick review. World J Gastroenterol 14: 6757-6759, 2008.

3. Agale SV, Agale VG, Zode RR, Grover S and Joshi S: Heterotopic pancreas involving stomach and duodenum. J Assoc Physicians India 57: 653-657, 2009.

4. Yuan Z, Chen J, Zheng Q, Huang XY, Yang Z and Tang J: Heterotopic pancreas in the gastrointestinal tract. World J Gastroenterol 15: 3701-3703, 2009.

5. Armstrong CP, King PM, Dixon JM and Macleod IB: The clinical significance of heterotopic pancreas in the gastrointestinal tract. Br J Surg 68: 384-387, 1981.

6. Trifan A, Târcoveanu E, Danciu M, Hutanasu C, Cojocariu C and Stanciu C: Gastric heterotopic pancreas: An unusual case and review of the literature. J Gastrointestin Liver Dis 21: 209-212, 2012.

7. Mehra R, Pujahari AK and Jaiswal SS: Duodenal heterotopic pancreatic tissue: A case report and literature review. Gastroenterol Rep Oxf pii: guo049, 2014 (Epub ahead of print).

8. Kim JH, Lim JS, Lee YC, Hyung WJ, Lee JH, Kim MJ and Chung JB: Endosonographic features of gastric ectopic pancreases distinguishable from mesenchymal tumors. J Gastroenterol Hepatol 23: e301-e307, 2008.

9. Kim JY, Lee JM, Kim KW, Park HS, Choi JY, Kim SH, Kim MA, Lee JY, Han JK and Choi BI: Ectopic pancreas: CT findings with emphasis on differentiation from small gastrointestinal stromal tumor and leiomyoma. Radiology 252: 92-100, 2009.

10. Otani Y, Yoshida M, Saikawa Y, Wada N, Kubota T, Kumai K, Sugino Y, Mukai M, Kameyama K and Kitajima M: Discrimination between gastric ectopic pancreas and mesenchymal tumors, including GIST - from 12 years' surgical experience in one institute. Aliment Pharmacol Ther 2: 292-296, 2006.

11. Lai EC and Tompkins RK: Heterotopic pancreas. Review of a 26 year experience. Am J Surg 151: 697-700, 1986.

12. Khashab MA, Cummings OW and DeWitt JM: Ligation-assisted endoscopic mucosal resection of gastric heterotopic pancreas. World J Gastroenterol 15: 2805-2808, 2009.

13. Hunt VC and Bonsteel HTS: Meckel's diverticulum containing aberrant pancreas. Arch Surg 28: 425-439 1934.

14. Klob J: Pancreas accessorium. J Imperial Royal Soc Physicians Vienna 15: 732, 1859 (In German).

15. Chandan VS and Wang W: Pancreatic heterotopia in the gastric antrum. Arch Pathol Lab Med 128: 111-112, 2004

16. Armstrong CP, King PM, Dixon JM and Macleod IB: The clinical significance of heterotopic pancreas in the gastrointestinal tract. Br J Surg 68: 384-387, 1981.

17. Weppner JL, Wilson MR, Ricca R and Lucha PA Jr: Heterotopic pancreatic tissue obstructing the gallbladder neck: A case report. J Pancreas 10: 532-534, 2009.
18. Artavanis-Tsakonas S, Rand MD and Lake RJ: Notch signaling: Cell fate control and signal integration in development. Science 284: 770-776, 1999.

19. Christodoulidis G, Zacharoulis D, Barbanis S, Katsogridakis E and Hatzitheofilou K: Heterotopic pancreas in the stomach: A case report and literature review. World J Gastroenterol 13: 6098-6100, 2007.

20. Seneviratne SA, Ramanayaka IT and Samarasekara DN: Heterotopic pancreas in the body of stomach. Ceylon Med J 54: 57-58, 2009.

21. Chen SH, Huang WH, Feng CL, Chou JW, Hsu CH, Peng CY and Yang MD: Clinical analysis of ectopic pancreas with endoscopic ultrasonography: An experience in a medical center. J Gastrointest Surg 12: 877-881, 2008.

22. Chak A, Canto MI, Rösch T, Dittler HJ, Hawes RH, Tio TL, Lightdale CJ, Boyce HW, Scheiman J, Carpenter SL, et al: Endosonographic differentiation of benign and malignant stromal cell tumors. Gastrointest Endosc 45: 468-473, 1997.

23. Philipper M, Hollerbach S, Gabbert HE, Heikaus S, Böcking A, Pomjanski N, Neuhaus H, Frieling T and Schumacher B: Prospective comparison of endoscopic ultrasound-guided fine-needle aspiration and surgical histology in upper gastrointestinal submucosal tumors. Endoscopy 42: 300-305, 2010.

24. Kobara H, Mori H, Fujihara S, Nishiyama N, Tsutsui K and Masaki T: Gastric Heterotopic pancreas can be identified by endoscopic direct imaging with submucosal endoscopy. J Gastrointestin Liver Dis 22: 345-348, 2013.

25. Von Heinrich H: Ein peitrang zur histrologie des sogen akzessorischen pancreas. Virchows Arch 198: 392-401, 1909.

26. Gaspar Fuentes A, Campos Tarrech JM, Fernández Burgui JL, Castells Tejón E, Ruíz Rossello J, Gómez Pérez J and Armengol Miró J: Pancreatic ectopias. Rev Esp Enferm Apar Dig 39: 255-268, 1973 (In Spanish).

27. Ormarsson OT, Gudmundsdottir I and Mårvik R: Diagnosis and treatment of gastric heterotopic pancreas. World J Surg 30: 1682-1689, 2006

28. Teke Z, Kabay B, Kelten C, Yilmaz M and Duzcan E: Ectopic pancreas of the gastric antrum contiguous to a gastrointestinal stromal tumor manifesting as upper gastrointestinal bleeding: Report of a case. Surg Today 37: 74-77, 2007.

29. Huang YC, Chen HM, Jan Y Y, Huang TL and Chen MF: Ectopic pancreas with gastric outlet obstruction: Report of two cases and literature review. Chang Gung Med J 25: 485-490, 2002.

30. Gurocak B, Gokturk HS, Kayacetin S and Bakdik S: A rare case of heterotopic pancreas in the stomach which caused closed perforation. Neth J Med 67: 285-287, 2009.

31. Sadeghi NR, Godambe A, Shienbaum AJ and Alloy A: Premalignant gastric heterotopic pancreas. Gastroenterol Hepatol (NY) 4: 218-221, 2008.

32. Kojima T, Takahashi H, Parra-Blanco A, Kohsen K and Fujita R: Diagnosis of submucosal tumor of the upper GI tract by endoscopic resection. Gastrointest Endosc 50: 516-522, 1999.

33. Ryu DY, Kim GH, Park DY, Lee BE, Cheong JH, Kim DU, Woo HY, Heo J and Song GA: Endoscopic removal of gastric ectopic pancreas: An initial experience with endoscopic submucosal dissection. World J Gastroenterol 28: 16: 4589-4593, 2010 .

34. Makarewicz W, Bobowicz M, Dubowik M, Kosinski A, Jastrzebski $\mathrm{T}$ and Jaskiewicz J: Endoscopic submucosal dissection of gastric ectopic pancreas. Wideochir Inne Tech Maloinwazyjne 8: 249-252,2013.

35. Faigel DO, Gopal D, Weeks DA and Corless C: Cap-assisted endoscopic submucosal resection of a pancreatic rest. Gastrointest Endosc 54: 782-784, 2001. 